\title{
Modelos de agricultura urbana para a segurança alimentar: um estudo comparativo entre Singapura e Brasil
}

O setor de agricultura urbana está se expandindo rapidamente no globo terrestre, tanto para uso comercial como residencial. Sua escala varia de pequenas parcelas de quintal em jardins comunitários e escolares, bem como grandes fazendas comerciais localizadas nas zonas urbanas e perí-urbanas das grandes cidades. A atividade tem se utilizado de operações hidropônicas a produzir vegetais até mesmo aquapônicas para produção de peixes em terraços prediais. Dessa maneira, 0 objetivo desse trabalho se pautou em compreender como a agricultura urbana auxilia a 'Segurança Alimentar' em uma análise comparativa entre Singapura e Brasil. A metodologia se pautou em pesquisa descritiva e exploratória utilizando suporte de registros fotográficos e depoimentos in locu. Os resultados preliminares apontaram diferenças significativas entre os modelos e formatos de agricultura urbana e a forma com que cada país lida com a questão da Segurança Alimentar. O Brasil (representado por Cuiabá/MT) apresentou uma agricultura urbana insipiente, de baixa escala e pouca qualidade técnica com atendimento a bolsões urbanos de extrema pobreza e carência de alimentos. Quanto ao país de Singapura os resultados apontam uma agricultura urbana consolidada com fazendas verticais e até fazendas em terraços prediais. O mesmo mostrou ser produtivo com elevado grau tecnológico, preocupação ambiental e social.

\section{Models of urban agriculture for food security: a comparative study between Singapore and Brazil}

The urban agriculture sector is expanding rapidly on the globe for both commercial and residential use. Their range ranges from small parcels of yard in community and school gardens, as well as large commercial farms located in urban and peri-urban areas of large cities. The activity has been used from hydroponic operations to produce even aquaponic vegetables for the production of fish on building terraces. Thus, the aim of this work was to understand how urban agriculture assists 'Food Security' in a comparative analysis between Singapore and Brazil. The methodology was based on descriptive and exploratory research using support of photographic records and testimonies in locu. Preliminary results pointed to significant differences between the models and formats of urban agriculture and the way in which each country deals with the issue of Food Security. Brazil (represented by Cuiabá/MT) presented a low - scale, low - quality, low - quality urban agriculture with assistance to urban pockets of extreme poverty and food shortages. As for the country of Singapore the results point to a consolidated urban agriculture with vertical farms until farms in terraces building. The same showed to be productive with high technological degree, environmental and social concern.

Keywords: Urban farms; Food Security; Hydroponics; Urban Agriculture.

Topic: Planejamento Urbano

Reviewed anonymously in the process of blind peer
Received: $10 / 02 / 2018$

Approved: $24 / 03 / 2018$
Leandro Pessoa de Lucena

Universidade Federal de Mato Grosso, Brasil

http://lattes.cnpq.br/0782095024954450

http://orcid.org/0000-0002-4938-336X

lepecena@hotmail.com

Claudio Eurico Seibert Fernandes da Silva (iD Universidade Federal de Mato Grosso, Brasil http://lattes.cnpq.br/6201010338201474

http://orcid.org/0000-0002-1703-9687

claudioseibertf@gmail.com

\section{Referencing this:}

LUCENA, L. P.; SILVA, C. E. S. F.. Modelos de agricultura urbana para a segurança alimentar: um estudo comparativo entre Singapura e Brasil. Revista Ibero Americana de Ciências Ambientais, v.9, n.3, p.379-397, 2018. DOI: http://doi.org/10.6008/CBPC2179-6858.2018.003.0030

DOI: 10.6008/CBPC2179-6858.2018.003.0030 


\section{INTRODUÇÃO}

A agricultura mundial está passando por uma transição para novos paradigmas tecnológicos impulsionados por inovações em sustentabilidade e eficiência no uso de recursos naturais. O desenvolvimento deste novo paradigma é possibilitado pelas atuais revoluções de 'precisão', 'inteligência artificial', e 'novas demandas de mercados'. Na pratica há dois grandes setores de produção de alimentos na agricultura mundial, sendo a mais conhecida por sua produção extensiva e patronal tendo como nome: Modelo rural agrícola ou Convencional alimentar, e a outra pouco difundida, porém em grande avanço técnico e científico, conhecida como: Modelo urbano agrícola ou Perí-urbano alimentar. Para Mougeot (2000) com certeza, o elemento mais comumente citado nas definições do que seja a agricultura urbana é o local onde ela é praticada: as cidades e seus arredores imediatos; porém mesmo esse elemento tem sido causa de um importante conflito conceitual.

Conforme, Barthel et al. (2015) não é possível identificar com precisão o momento histórico e exato em que a Agricultura Urbana começou, uma vez que existem muitos pontos de vista diferentes sobre o assunto. Alguns apontam o seu início com os primeiros assentamentos de pequenas populações antes mesmo das revoluções industriais, enquanto outros acreditam que foi um processo mais recente dado uma necessidade para o cultivo de alimentos em áreas urbanas, a fim de atender com maior rapidez a necessidade de consumo das populações locais.

Porém para Lucena (2016) há fatos históricos registrados em ilustrações de quadros antigos que datam entre o final do século 19 e o início do século 20, em que a agricultura europeia em meio a revolução industrial esboça os primeiros edifícios agroindustriais no velho continente. Essas dimensões arquitetônicas no meio urbano apresentavam famílias europeias de colonos que se deslocaram para o meio urbano e possuíam fortes ligações com a terra e com o valor sentimental ao campo. Os inúmeros edifícios do meio urbano serviram naquela época muito mais do que uma simples moradia ou local de resguardo noturno. Ou seja, os 'arranha céus' foram também uma extensão das atividades de agricultura familiar. Era comum aos edifícios possuírem pequenas hortas coletivas ou individuais em seus terraços, ou até mesmo criações de pequenos animais para consumo próprio, como cordeiros, coelhos e aves. Porém a história também dimensiona momentos sombrios do desenvolvimento da agricultura urbana no mundo, pois o período entre guerras, tanto na primeira quanto na segunda guerra mundial, foram dias de ausência de produção agrícola urbana. Nesse período, as cidades ficaram em ruinas, bem como, a coragem e o anseio da população local suplantados em luto e dor.

Em suma esse trabalho tem como objetivo comparar modelos de agricultura urbana entre os países de Brasil (representando por Cuiabá/MT) e Singapura, no intuito de melhor compreender como essa atividade econômica atua na perspectiva da 'Segurança Alimentar' de cada país. Para tanto, essa analise se torna justificável acerca do debate de modelos alternativos de produção rural urbano que tenha finalidade a contribuir com produção de alimentos que gere menor quantidade em emissão de $\mathrm{CO}_{2}$ na atmosfera e que 
estejam associados ao bem-estar social das populações urbanas ou perí-urbanas tanto no presente como no futuro.

\section{REVISÃO TEÓRICA}

Segundo Barthel et al. (2015) no final da década de 90 a Organização das Nações Unidas para a Alimentação e Agricultura - FAO, dimensionou pela primeira vez definições sobre Agricultura Urbana categorizando a mesma resumidamente em quatro segmentos, como: Fazendas Comunitárias, Fazendas Comerciais, Fazendas Institucionais e por fim Jardins Comunitários. (Figura 1). Ainda naquela época o estudo trouxe as primeiras contribuições ao que se refere os benefícios da Agricultura Urbana para populações locais que já estavam fazendo uso da mesma, como Japão, Holanda, Coréia do Sul, EUA, Canadá, entre outros. Os benefícios puderam ser dimensionados desde: melhorias a saúde física e mental da população, maior envolvimento social da comunidade, maior estabilidade econômica entre os agentes envolvidos, até mesmo a percepção de maior amadurecimento e conscientização ecológico - ambiental dos cidadãos.

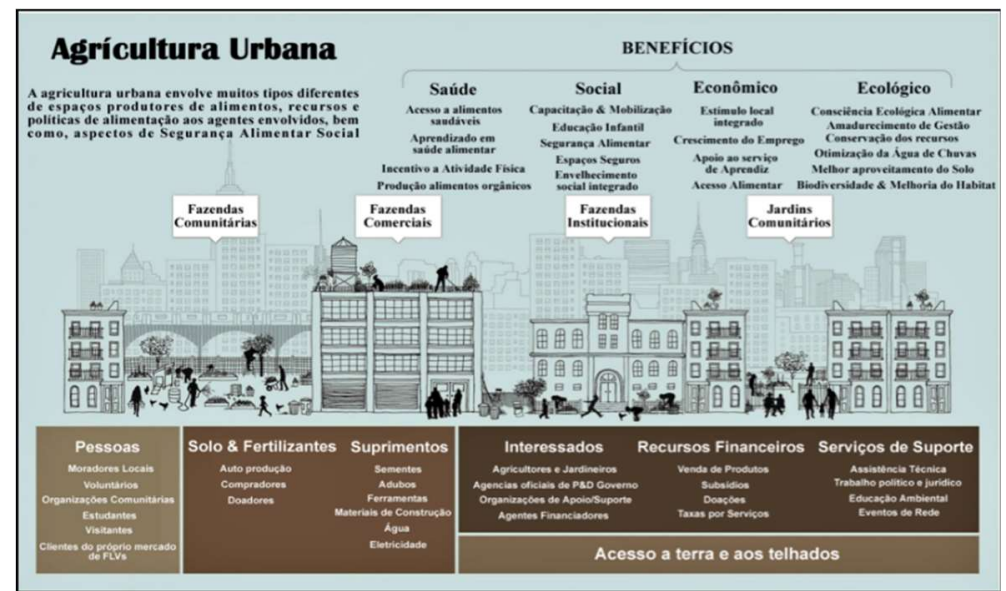

Figura 1: Dimensões da agricultura urbana década 90. Fonte: Adaptado de FAO (2016).

Sendo assim, as 'fazendas comunitárias ou agricultura compartilhada' passou a ser entendido como modelo de base econômica local baseado na produção e distribuição de alimentos a uma rede particular, ou associação de indivíduos, que se comprometem em apoiar esforços em plantar, colher, e consumir seus próprios vegetais, além do fato de partilhar os riscos e benefícios da produção de alimentos perecíveis. As fazendas comunitárias se diferenciam por serem hortas em terrenos ou espaços públicos e privados, com ou sem presunção para fins lucrativos (LORENZ, 2015).

Já as 'fazendas comerciais', estas teriam utilização de ferramentas mais avançadas de produção agrícola, fazendo uso de estufas horizontais ou verticais e maior controle dos recursos naturais como: otimização da água (técnica de hidroponia e aeroponia) e melhor aproveitamento da terra ou espaço físico (produção verticalizada). O mesmo teria foco de sua produção a consumidores diretos ou indiretos como: mercados, restaurantes, hotéis, entre outros LUCENA (2014). Quanto as 'fazendas institucionais' são produções agrícolas de fins privado ou público para uma delimitada clientela. Convencionalmente produções de vegetais em escolas, creches, asilos, penitenciarias, igrejas ou universidades para fins de experimento e/ou consumo direto (MCCLINTOCK et al., 2016). Por fim, os 'Jardins comunitários' sendo um espaço coletivo 
e planejado, normalmente ao ar livre, para a exibição, cultivação e apreciação de plantas, flores e outras formas de natureza. Esse segmento faz parte da agricultura urbana como consumo de lazer ou também conhecido como consumo agroturístico (MARTIN et al, 2016).

Segundo, Lorenz (2015) de uma perspectiva global, a agricultura urbana é responsável por 15 a 20\% da produção agrícola total mundial. Além disso, agricultura urbana não é apenas o processo de cultivo de alimentos, mas também a criação de pequenos animais, a produção de flores, ervas medicinais, plantas ornamentais e arvores de pequeno e médio porte. Em síntese, sabe - se que a Agricultura Urbana ao longo de toda década de 90 envolveu aproximadamente 800 milhões de pessoas em todo globo terrestre, cobrindo mais de 67 milhões de metros quadrados ou equivalente 5\% da área total de cultivo global. 0 fato negativo é que embora o número de estudos sobre atividades agrícolas em solos urbanos relativamente crescesse na última década, o enfoque multidisciplinar ainda têm sido negligenciado com poucas abordagens acadêmicas cientificas a novos segmentos e subsegmentos da agricultura urbana, como exemplo as 'Fazendas Verticais' e as 'Hortas Gourmet Automatizadas' (LUCENA, 2016).

\section{Dimensão teórica da agricultura urbana pós década de 90}

Segundo, Souto (2017) após duas décadas das primeiras definições de Agricultura Urbana pela Organização das Nações Unidas para a Alimentação e Agricultura - FAO, a atividade de agricultura urbana atualmente pode ser dividida em duas grandes modalidades, isto é, 'Alimentar' e 'Não- Alimentar (outros produtos)'. A modalidade alimentar passou a ser dividida em três grandes segmentos, ou seja: 'Orientado para o Mercado', 'Orientado para a comunidade' e por último o segmento 'Situacionista' (Figura 2).

Conforme, Warming et al. (2015) o Segmento Situacionista está atrelado a participação de cidadãos comuns a produção de suas necessidades imediatas e/ou comerciais, convencionalmente aquilo que se conhece como agricultura familiar, porém no ambiente urbano. Esses 'Agentes locais Atuantes' se tornou uma categoria que pode ser orientada para o mercado ou para a comunidade local, dependendo das decisões das partes interessadas. O mesmo também pode assumir características de produções agrícolas compartilhado, caso de jardins, terrenos públicos e/ou privados com metas a beneficiarem programas sociais da comunidade ou simplesmente atenderem a interesses privados. Este grupo é talvez o mais difícil de categorizar devido a suas muitas formas e nuanças.

Quanto ao segmento 'Orientado para a comunidade' esse passou ser dividido em várias subcategorias de agricultura urbana. Os 'Parques urbanos' conforme Martin et al. (2016) são de produção agrícola intensiva e de médio a grande porte. 0 mesmo pode ser orientado para o mercado ou para a comunidade. Há muitos parques urbanos europeus que são utilizados para produção apícola, ou manejo da piscicultura de cativeiro, entre outras atividades. Em relação aos 'Jardins urbanos' segundo Specht et al. (2016) são micro ou pequenos jardins voltados para os programas da comunidade, mas também pode obter lucro através da venda de produtos como raízes medicinais e flores. Pode ser uma combinação de engajamento social e ambiental. 
Os 'Jardins de casa ou residencial' esses são considerados pequenas produções agrícolas, que se aplicam em alimentar as pessoas da dita residência. Para Carolan et al. (2016) essas produções se restringem a pequenas hortas e/ou pequenas produções de frutas, legumes e verduras. Quanto aos 'Jardins Institucionais' estão presentes em instituições e/ou organizações, como jardins de igrejas, jardins de hospitais ou jardins universitários. Outros exemplos incluem também as fazendas escolares, jardins escolares e programas escolares (POTHUKUCHI et al., 2015). Já as 'Terras Ociosa', essas correspondem a parcelas ou territórios que não foram utilizados ou abandonadas devido à necessidade de deslocalização. É bem citada na literatura científica em cidades como Detroit e Chicago nos Estados Unidos, que sofreram um processo de declínio industrial. A terra ociosa também é conhecido na agricultura urbana como Lotes Vacantes, (PÖLLING, 2016).

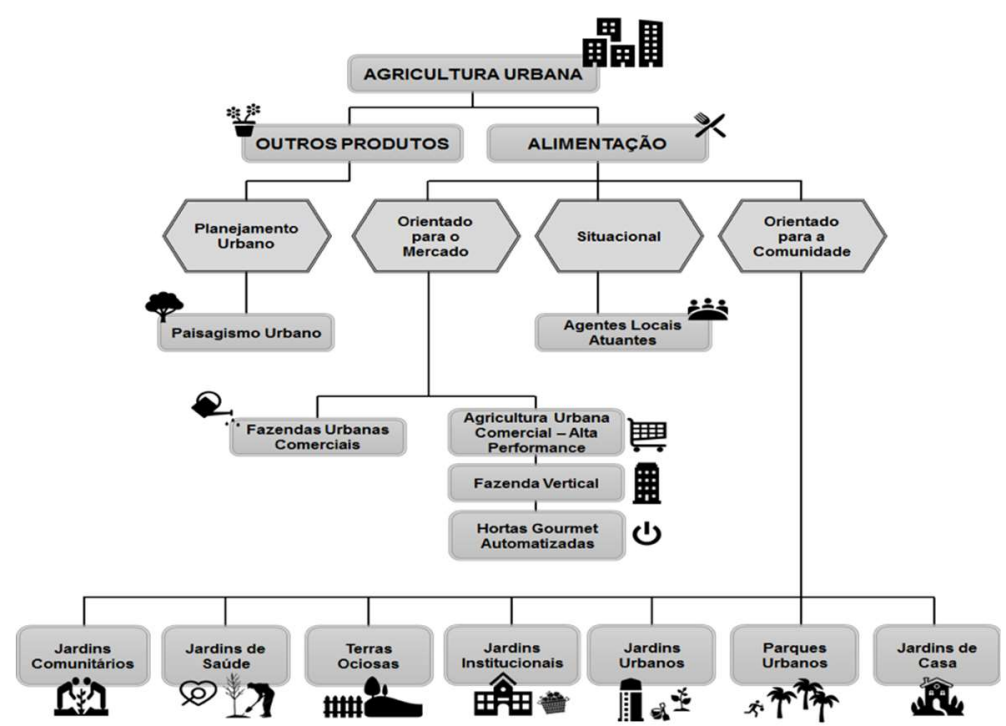

Figura 2: Categorias e subcategorias da atividade de agricultura urbana. Fonte: Adaptado de Souto (2017).

Os 'Jardins de saúde' conforme menciona Witheridge et al. (2016) são espaços físicos em meio aos centros urbanos com produções em pequenas escalas de árvores, flores, relvas nas quais o foco principal está na garantia da boa saúde mental e física aos participantes que se dá através do tratamento com a natureza. É relacionado à jardinagem como uma atividade de passatempo. O sentido dos jardins de saúde é essencialmente para fins Terapêuticos. Por último, os 'Jardins comunitários', esses são terrenos agrícolas urbanos administrados e compartilhados por grupo de moradores que se dedicam à horticultura para fornecer alimentos locais, benefícios físicos e sociais aos participantes, em espaços que proporcionam uma ligação direta entre produtores e consumidores. Muitas vezes, os projetos impulsionados pela comunidade dependem de organizações sem fins lucrativos ou agências para funcionarem coletivamente ou em cooperação (CAROLAN et al., 2016).

Em relação ao segmento 'Orientado para o mercado' a mesma é dividida em 'Fazendas urbanas comerciais' que possui característica de iniciativas empresariais ou sem fins lucrativos. No entanto, há trabalhadores que operam a produção agrícola via contratos, e o mesmo é orientada para o mercado e a escala de produção pode variar. Os modelos mais comuns são produções de verduras e legumes em estufas horizontais próximas ao perímetro urbano Rogus et al. (2015). Outra modalidade do segmento ‘Orientado 
para o mercado' é identificada como 'Agricultura urbana comercial de alta performance', está também se concentra no lucro e é orientada para o mercado. Se difere das Fazendas urbanas comerciais da maneira que é produzido. Pode variar de telhados com ou sem estufas, como edifícios totalmente integrados ou ainda produção de estufas verticais (LUCENA et al., 2015).

Por hora as 'Fazendas Verticais' se caracterizam pela prática de produção de alimentos em camadas empilhadas verticalmente, tais como arranha-céus, em armazéns ou até mesmo em terraços de prédios urbanos. As ideias modernas das fazendas verticais estão no uso de técnicas de cultivo fechado com total controle tecnológico do ambiente, onde todos os fatores ambientais podem ser controlados. Estas instalações utilizam controle artificial da luz do ambiente (umidade, temperatura, gases, etc.) e fertirrigação, (LUCENA, 2016).
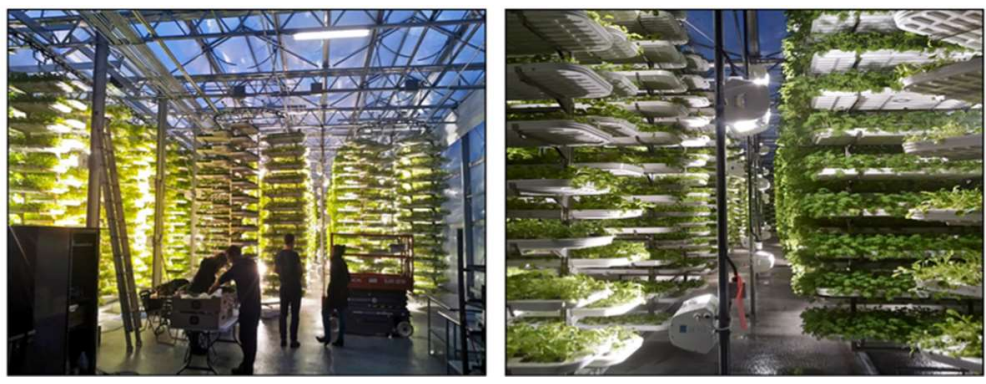

Figura 3: Modelo de fazenda vertical da agroindústria Alterrus localizado em Vancouver/Canadá. Fonte: Adaptado de Lucena (2014).

Outro fator de destaque das fazendas verticais urbanas em relação ao modelo horizontal é que convencionalmente as fazendas verticais fazem uso da tecnologia Verticrop, que procura assim maximizar o uso do espaço físico, além de eliminar a necessidade de herbicidas ou pesticidas no desenvolvimento das mudas, tornando os produtos mais frescos, mais saudáveis e aprazível aos clientes da comunidade local. No exemplo da figura 3, a fazenda Vertical Alterrus localizada em Vancouver - Canadá faz uso do sistema de cultivo Verticrop, onde as torres de inox a qual dão suporte às bandejas para produção agrícola possuem um raio de 1,6 $\mathrm{m}$ de comprimento (raio) por 3,3 $\mathrm{m}$ de altura. Seu rendimento corresponde a uma área de 9 (nove) vezes a sua própria circunferência, ou seja, a um espaço horizontal de $14,4 \mathrm{~m}^{2}$, possuindo ainda uma produtividade agricultável de até 10 (dez) vezes mais que a agricultura convencional.

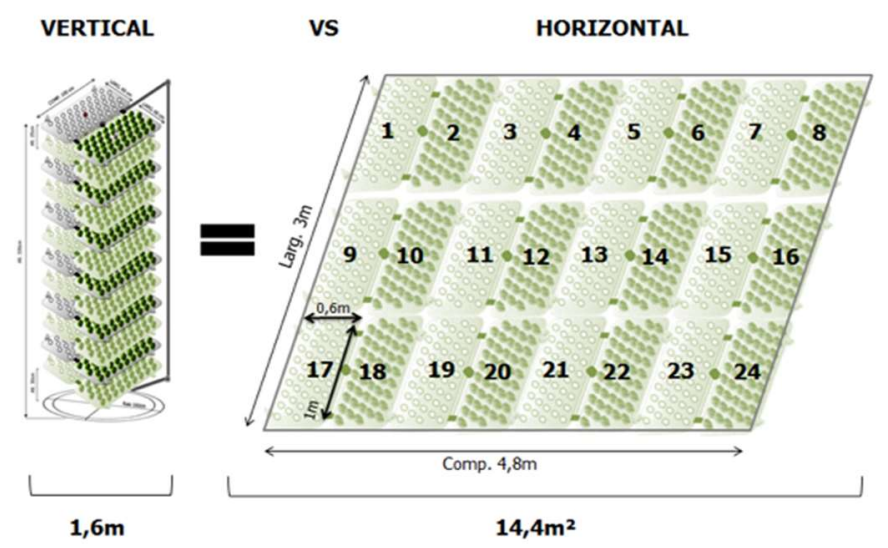

Figura 4: Relação de aproveitamento de espaço físico da Fazenda Vertical em relação a Horizontal. Fonte: Adaptado de Lucena et al. (2015b). 
Por último, as 'Hortas gourmet automatizadas' como sendo a nova forma de plantar e colher vegetais dentro de casa e/ou apartamentos. Esse segmento da Agricultura Urbana é a mais nova modalidade em levar a agricultura convencional de produção de pequenos vegetais para dentro de cada lar. Convencionalmente são máquinas desenvolvidas por agroindústrias que se apropriaram das tecnologias de 'mini - incubadoras' para uso doméstico. Grande maioria dessas maquinas são automatizadas, possuem feixes internos ou externos de OLEDs, ventilação e reservatório de nutrientes aos vegetais. A função da mesma é revolucionar os lares urbanos introduzindo uma horta do quintal para dentro das casas, ou simplesmente um eletrodoméstico de uso convencional sem a necessidade de amplo conhecimento em plantar ou colher por parte do usuário que venha fazer uso do aparelho. Essa revolução da agricultura urbana promete produzir verduras e hortaliças em geral com o conceito de colheita e consumo direto de alimentos orgânicos estilo gourmet (LUCENA, 2016).
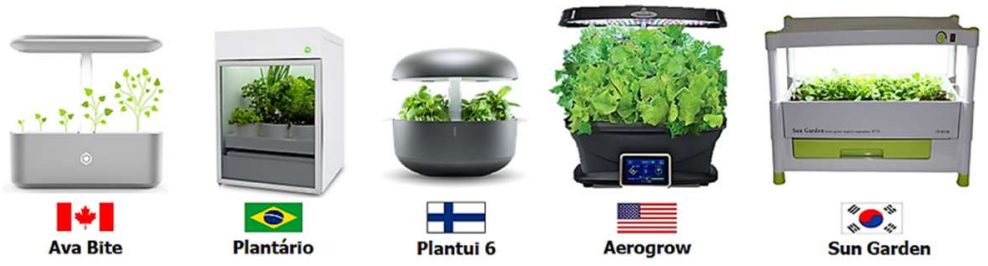

Figura 5: hortas automatizadas estilo gourmet. Fonte: Adaptado de Lucena (2016).

Em relação a modalidade 'Não - Alimentar' da Agricultura Urbana, a mesma está voltada especificamente ao segmento de Planejamento Urbano das grandes cidades. Esse por hora possui a atividade de Paisagismo Urbano (subsegmento) responsável em ajudar a mitigar o clima e os problemas ambientais, bem como embelezar as cidades e seus arredores. Conforme (LUCENA et al., 2014) essa modalidade está se tornando comum nas grandes cidades com aparecimento de telhados verdes, paredes e fachadas verticais com vegetais, flores, arbustos, entre outros. O avanço urbanístico está percebendo o potencial desses sistemas vivos para aumentar a qualidade do ambiente construído, a fim de proporcionar benefícios sociais, estéticos, ambientais e econômicos. Os especialistas nesse segmento têm dado o nome de envelopamento de edifícios, a qual constitui todos os elementos de construção incluindo paredes, fundações, telhado, janelas e portas consorciados a vida ao ar livre, e somado ao habitat com sistemas vivos.
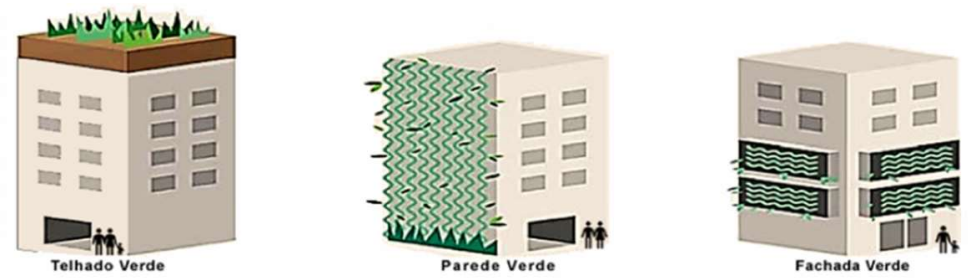

Figura 6: Formas de agricultura urbana em edifícios. Fonte: Adaptado de Suparwoko et al. (2017).

O segmento de prédios denominado 'Telhado verde' constitui uma paisagem de vegetação construída a partir de uma série de camadas que são instalados sobre a superfície do terraço de um prédio, normalmente são módulos soltos e instalados camada por camada, e pré-preparados em bandejas. Quanto a vegetação dos telhados verdes, a mesma é estabelecida em meio ao objetivo que pode variar em 
profundidade de $50 \mathrm{~mm}$ ou para mais de um metro, dependendo da capacidade de carga do telhado do edifício e os desígnios do projeto. Ressaltando que os telhados verdes são construídos como uma série de camadas, cada uma das quais executa uma função específica. As atividades mais típicas são mostradas na figura 7.
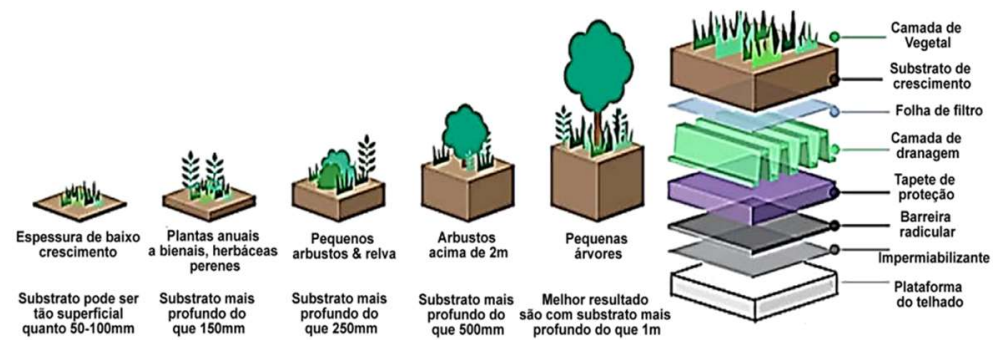

Figura 7: Construção de telhados verdes em edifícios. Fonte: Adaptado de Suparwoko et al. (2017).

Já um prédio envelopado com 'Parede verde', esse é composto de plantas cultivadas na vertical ${ }^{1} \mathrm{com}$ sistemas que são geralmente anexados a um suporte em paredes externas ou internas, embora em alguns casos possam ser independentes. Há casos de edifícios com 'telhados verdes', que também incorporam 'paredes verdes' em sua vegetação. 0 meio de crescimento, irrigação ${ }^{2}$ e drenagem desses vegetais podem utilizar um único sistema. Para maior entendimento do modelo de construção, bem como, as técnicas do envelopamento de uma 'Parede verde' são apresentadas figura a seguir.

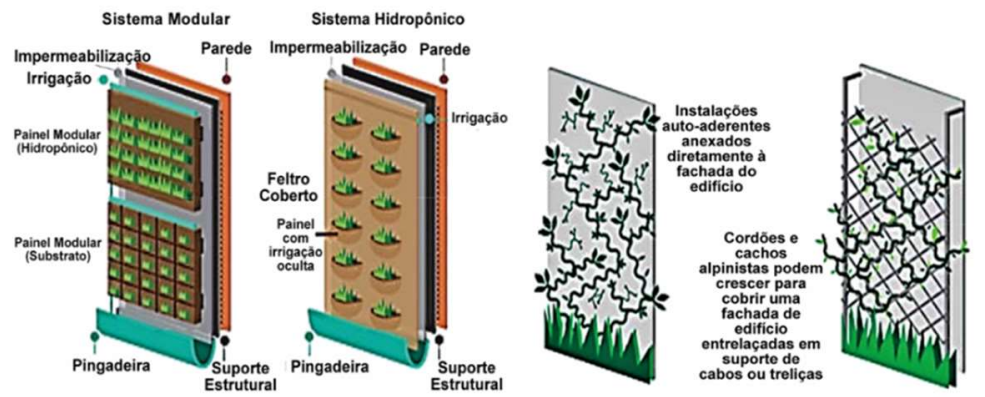

Figura 8: Construção de paredes verdes em edifícios. Fonte: Adaptado de Suparwoko et al. (2017).

Um prédio com "fachada verde" é caracterizado pela agricultura urbana como cultivo de plantas de escalada em toda a fachada ou parte dela, ou a partir de plantas cultivadas em canteiros de base ou recipientes plantados e instalados em diferentes níveis ao longo do edifício. Conforme Suparwoko et al. (2017) plantas de escalada podem ser anexadas diretamente a superfície de um edifício, ou também serem apensadas em uma estrutura independente do arranha-céu. Sabe - se também que o uso de plantas alpinistas que se ancoram numa estrutura por hastes entrelaçadas ou por entrelaçamento de gavinhas possibilita fachadas verdes serem instaladas na frente de paredes sólidas ou alguma outra estrutura, a fim de criar uma partição ou até mesmo tela de privacidade ou de 'para-sol'. O grau de densidade da cobertura da fachada pode ser gerenciado de acordo com a função desejada.

\footnotetext{
${ }^{1}$ A verticalização das plantas são verdadeiras paredes vivas. Elas colaboram substancialmente com a diminuição dos efeitos da emissão de carbono e diminuem a temperatura do ambiente pelo controle da energia solar (DOANE, 1950).

${ }^{2} \mathrm{O}$ sistema de irrigação na parede usa uma rega automática com temporizador e pompa. A água é canalizada através de um gasoduto e distribuída para todas as linhas da planta. Os potes ou feixes de sustentação são feitos de plástico com muitos furos pequenos para fornecer uma maneira para que a água flua para o interior da planta, ou mais especificamente por seu caule. Todo esse processo é utilizado cordões de lã com substrato de rocha para cada planta (LUCENA, 2014).
} 
Em síntese a atividade econômico, ambiental e social da agricultura urbana e seus segmentos de atuação 'alimentar como não-alimentar' carecem de mais pesquisa sobre suas funcionalidades e particularidades de atuação dependendo do país em que ocorrer a análise. Porém, como atuação de políticas públicas essa pode ser uma atividade potencial de bem-estar social as gerações futuras, bem como, ferramenta de conscientização do ecossistema por boa parte da população. Por outro lado, o que se pode afirmar conforme (UGAl, 2016) das vantagens sustentáveis de ser 'verde' primordialmente os prédios que assim são chamados atualmente, é que a cobertura desses podem ser projetadas para coletar água da chuva e reduzir o uso de água potável. Em segundo lugar, a adaptação de um telhado verde não só pode diminuir efetivamente a quantidade de escoamento de águas pluviais, mas também mitigar o nível de calor e seus efeitos, prolongando assim a vida útil do telhado e melhorando o desempenho de isolamento térmico e acústico. Em terceiro lugar, a cobertura da agricultura inclui alguns benefícios por ser telhado verde, como subproduto, os alimentos podem ser cultivados em um núcleo urbano, reduzindo a pegada de carbono.

\section{METODOLOGIA}

Esse trabalho caracterizou por ser um estudo descritivo e exploratório, que segundo Gil (1991) e Richardson (1999) devem ser realizados quando um tema é pouco explorado ou quando as informações estão muito pulverizadas, tornando difícil a formulação de hipóteses precisas e operacionalizáveis. Sendo assim, a pesquisa de campo dividiu em duas etapas. A primeira etapa pela escolha das áreas administrativas ou macrorregiões que seriam mapeadas, a fim de analisar tipos de agricultura urbana existentes entre Brasil (representado por Cuiabá/MT) e o país de Singapura (denominado internacionalmente por ser um PaísEstado-Cidade). Na segunda etapa, elaborar uma 'matriz sintética comparativa' dos tipos de agricultura urbana identificadas em ambos países e determinar pontuações positivas ou negativas segundo características técnicas, econômicas, ambientais e sociais.

A pesquisa de campo no Brasil (representando pelo munícipio de Cuiabá/MT) foi realizada entre os meses de agosto e outubro de 2017. A escolha desse município ocorreu pela forte contraditoriedade em relação aos aspectos de Segurança Alimentar do município. Pois, Cuiabá/MT é uma das capitais brasileiras conhecida por ser o celeiro agroindustrial do mundo, no entanto apresenta níveis elevados de insegurança alimentar conforme estudos do Instituto de Pesquisa Econômica Aplicada - IPEA e do Programa nacional por amostra de domicílios - Pnad. Dados apontam a insegurança alimentar da capital mato-grossense muito ao fato dos vegetais apreciados nas gondolas de os supermercados do município possuírem preços elevados e isso consequentemente gerar baixo consumo da população por Frutas, Legumes e Verduras - FLV's. Por conta desses fatores buscou averiguar as formas de agricultura urbana e familiar que o município adota, bem como as políticas públicas de apoio ao segmento.

A outra pesquisa de campo, a fim de comparar com a região de Cuiabá/MT (Brasil), foi realizada no país de Singapura no continente asiático entre os meses de novembro a dezembro de 2017. A escolha desse 
pequeno país ${ }^{3}$, essencialmente urbano se deu devido a quase inexistência de terra e demais recursos naturais do país em produzir alimentos, pois mais de $95 \%$ do consumo de alimentos desse país é importado conforme dados do (PNUD,2017). Porém sua agricultura urbana é considerada por muitos órgãos internacionais como a mais avançada e desenvolvida tecnologicamente no globo terrestre. Diante de tais pressupostos buscou averiguar através de uma pesquisa in locu os modelos de agricultura urbana existentes no país de Singapura e como seu governo lida com a questão da segurança alimentar.

\section{RESULTADOS}

A busca de melhor compreender como países extremamente diferentes em recursos naturais como em âmbito cultural, econômico e político, nesse caso: Singapura e Brasil (representado por Cuiabá/MT) lidam com a agricultura urbana, a fim de auxiliar a Segurança alimentar a suas populações. Procurou averiguar o que cada região melhor possuía em fazendas urbanas e que estivessem localizadas nos perímetros urbanos e perí-urbanos. Logo o que se observou no caso do Brasil representado pela cidade de Cuiabá/MT, a qual é 4,5 vezes maior que o País de Singapura, a cidade possui uma agricultura urbana insipiente de baixa escala e de pouca qualidade e boa parte de suas fazendas urbanas estão de certo modo pulverizadas nos inúmeros bolsões urbanos de extrema pobreza e de carência de alimentos como Frutas, Legumes e Verduras - FLVs sob a mesa das comunidades.

Porém há um esforço de algumas instituições em propiciar as comunidades locais acesso a vegetais ao consumo direto como a obtenção dos mesmos sem custos. A Mini fazenda urbana do Centro de Referência em Assistência Social (CRAS) - Dr. Bento Machado Lobo é uma dessas instituições. Essa está localizado no bairro Tijucal (região sul do município de Cuiabá/MT). A horta faz parte do projeto de revitalização e avanço da agricultura urbana proposto pela prefeitura no final de setembro de 2017. 0 objetivo principal da criação do ambiente produtivo de vegetais, foi fazer o uso tanto para consumo quanto para agregar valores às atividades da instituição. A área conta com uma variedade de mais de dez tipos de hortaliças como cebolinha, manjericão, alface, anador, entre outros vegetais.
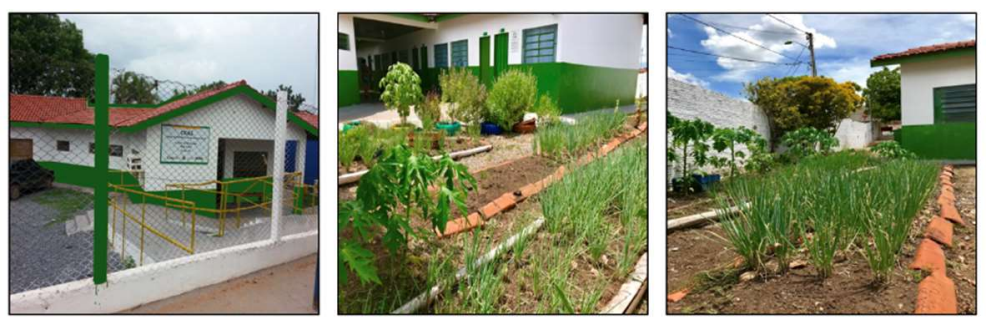

Figura 9: Mini fazenda CRAS-Dr. Bento Machado Lobo.

Em síntese a mini fazenda do 'CRAS' atende a cerca de 50 a 80 crianças diárias, com idades entre 6 e 17 anos. Sua área de abrangência integra a 32 bairros na região urbana do Coxipó. Algumas dificuldades apresentadas pela coordenadora do CRAS, tem sido a ausência de continuidade e apoio do projeto por parte dos órgãos governamentais, ou seja, os recursos para manutenção e continuidade da fazendinha como

\footnotetext{
${ }^{3}$ O país de Singapura (País - Cidade - Estado) possui 719,1 km² em dimensão territorial (PNUD, 2017). 
compras de sementes e mudas de vegetais, bem como custos com a preparação e material orgânico como adubo ou algum tipo de defensivo agrícola natural são todos custeados com o próprio bolso dos servidores. Além da dificuldade da ausência de um profissional em agronomia para ceder orientações sobre os cuidados com as hortaliças, horários para regar, quando realizar colheita, entre outras dicas.

Outra instituição de produção coletiva de vegetais, bem como consumo local foi encontrada na zona perí-urbana de Cuiabá, ou seja, a Escola municipal Nossa Senhora da Penha de França, a qual está localizado no 'distrito de Coxipó do Ouro'. O objetivo desse projeto segundo Mirian Zanca atual coordenadora do colégio 'tem sido trabalhar a horta escolar como espaço de aprendizagem para os alunos, por meio de conhecimentos e habilidades que Ihes permitam produzir e consumir alimentos saudáveis, além de contribuir com a inserção de mais legumes e verduras na alimentação escolar e familiar'.
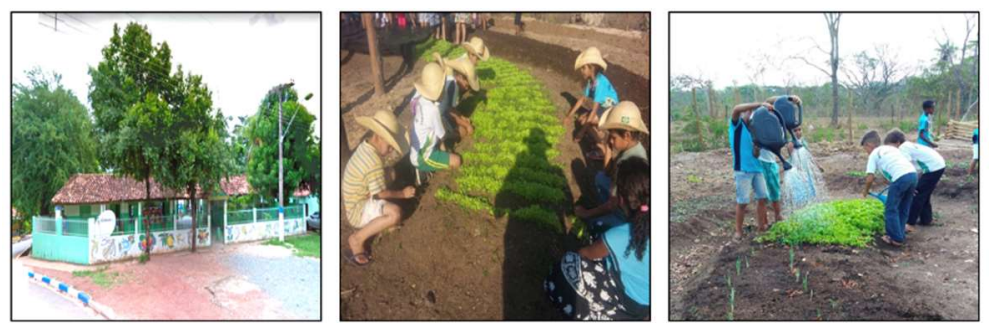

Figura 10: Horta escolar do Colégio Nossa Senhora da Penha de França na região Perí-urbana de Cuiabá/MT.

A dificuldade encontrada pela Escola municipal Nossa Senhora da Penha de França é que a horta escolar, praticamente todos insumos produtos para manutenção e continuidade da mesma tem sido doado pelos professores e pais dos alunos dado ausência de apoio financeiro da prefeitura. Praticamente toda a produção tem servido aos 350 a 400 alunos matriculados regularmente no colégio, a fim de subsidiar a merenda escolar.

Por fim, foi encontrado e observado na zona urbana de Cuiabá/MT, uma instituição um pouco mais profissional a produção de vegetais. O espaço Conexão Verde Vitória nasceu do Programa de Inclusão Socioambiental criado pelo Instituto Centro de Vida (ICV), um Programa com mais de uma década de atividades, no bairro Jardim Vitória, em Cuiabá/MT (zona norte).
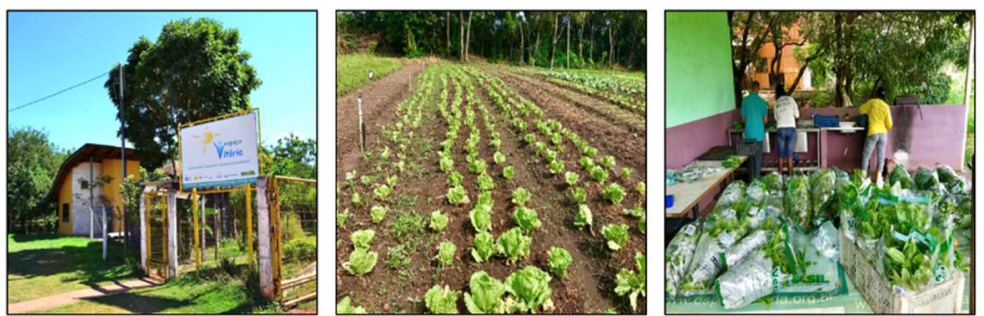

Figura 11: Fazenda urbana da Cooperativa Conexão Verde Vitória em Cuiabá/MT.

Desde que se instalou na região, um local com múltiplas carências de serviços públicos e desigualdades sociais, o Espaço Vitória vem favorecendo a transformação social da comunidade ao promover ações de geração de renda e desenvolvimento da cidadania, nos parâmetros da economia solidária e da sustentabilidade. Entre as atividades fundamentais da Cooperativa Verde Vitória está a compostagem de resíduos orgânicos oriundo de supermercados, restaurantes e de grandes geradores. Pelo processo de 
compostagem os resíduos são transformados em adubo orgânico que, em seguida, é utilizado em hortas livres de fertilizantes químicos e agrotóxicos. A produção agroecológica de hortaliças, obtida a partir da compostagem, gera renda para pessoas da comunidade que estavam em situação de vulnerabilidade socioeconômica. Todos os vegetais são comercializados para redes de supermercados, consumidores do entorno da sede e ao público como um todo e até mesmo através de sua Loja Virtual.

Agora expondo os resultados encontrados no país de Singapura os primeiros dados de sua agricultura e consumo conforme relatórios da Ásia consome $75 \%$ de todos os vegetais produzidos mundialmente e Singapura contribui com $9 \%$ desse volume, do repolho aos rabanetes chineses que formam a base do kimchi de grampo coreano até a plantação medicinal de folhas japonesas como: shisô, ênula, ginseng, entre outros. Vários foram os modelos e formatos de agricultura urbana observados em Singapura e que estão presentes em todas as suas 5 macrorregiões urbanas administrativas. A figura 12 retrata a fazenda urbana UpGrown Farming Company, a mesma é uma agroindústria de pequeno e médio porte que adota a metodologia ZipGrow $^{\text {TM }}$ de produção de vegetais, isto é um equipamento vertical em formato de torres, a qual sua função é acomodar os vegetais já em fase de crescimento (após 1 semana de vida).
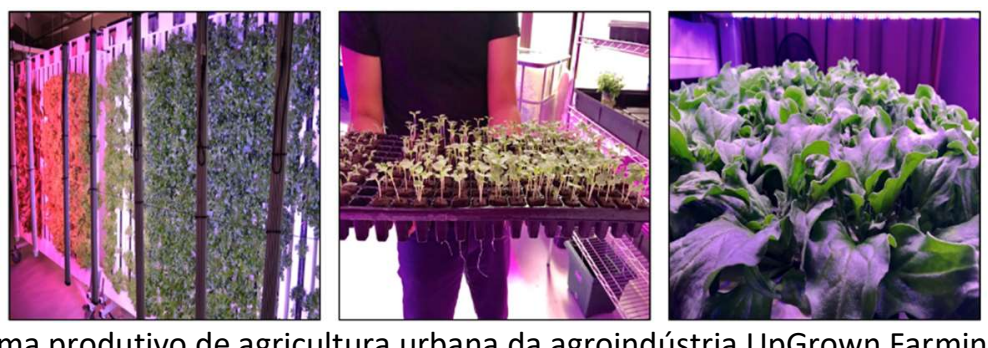

Figura 12: Sistema produtivo de agricultura urbana da agroindústria UpGrown Farming de Singapura.

As estruturas de inox consorciadas a PVC rígidos teriam o papel de imitar as condições naturais de uma produção agrícola convencional promovendo a alimentação continua e controlada aos vegetais através de uma solução nutritiva automatizada via sistema hidropônico por gotejamento superior das torres seguindo para partes inferiores. Já os diodos de LEDs fixados a cada torre fazem o papel da luz solar através de luzes modificadas com comprimentos de ondas ajustadas dependendo da cultura a qual está sendo produzida, a fim de auxiliar a fotossíntese dos vegetais para seu rápido desenvolvimento. Toda produção da UpGrown Farming atende os supermercados, quitandas e restaurantes locais.

Já a agroindústria de vegetais urbanos intitulada Citiponics, localizada em Singapura na estrada de Kang Ching, se faz presente em um telhado de estacionamento de vários andares de um condômino privado, onde inúmeras torres de 1,8 $\mathrm{m}$ de altura e alinhadas uma ao lado da outra são cobertos de vegetais verdes frondosos e se destacam aos olhos de quem passa aos arredores dos prédios e visualizam aos céus. A metodologia de produção aqui utilizado é conhecida como AOS (Aqua Organic System), a qual determina o uso racional de água em até $90 \%$ dado comparação a produção agrícola convencional, se mostrando também muito higiênica e anti-mosquitos ou reprodutores de vetores. Em relação aos produtos colhidos do jardim Citiponics, esses são ofertados e distribuídos aos moradores que vivem no próprio condomínio e posteriormente no bairro por meio das boutiques de vegetais existentes nos supermercados locais. 

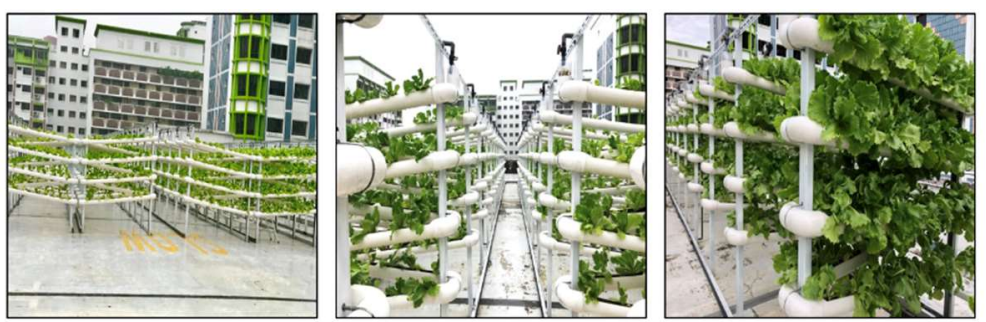

Figura 13: Sistema produtivo de agricultura urbana da agroindústria Citiponics Farming de Singapura.

A agroindústria SkyGreens, mais conhecido em português como 'Vegetais no céu' é a invenção local de propriedade privada do senhor Jack Ng de 48 anos de idade. Essa fazenda urbana está localizada em Lim Chu Kang Lane 3 na região: Sul-oeste de Singapura. A mesma é considerada a maior fazenda urbana da Ásia com a missão de tornar a agricultura vertical a atividade de maior rendimento produtivo da história, ou seja, produzir cinco a seis vezes mais do que normalmente se produz com a mesma quantidade de terra.
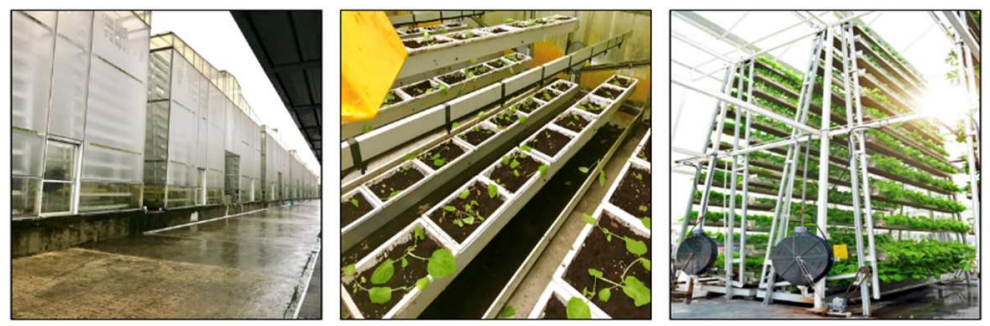

Figura 14: Sistema produtivo de agricultura urbana da agroindústria Skygreens Farm.

Com a implementação da fazenda Skygreens Farm é produzido mais de 1.000 toneladas de vegetais (FLVs) por hectare/ano. Além disso, os vegetais da fazenda Skygreens Farm levam cerca de 4 horas para a colheita diária e 30 minutos para chegar às prateleiras em supermercados, restaurantes, hotéis, bares e boutiques de vegetais locais. Toda sua produção é vendida antecipadamente via contrato futuro.

Em relação aos formatos de agricultura urbana que envolve setores da sociedade singapuriana mais perí-urbanas ou indivíduos com menor poder aquisitivo, a escola Hillside World Academy (ver fig.15) acredita na construção de valores a nova sociedade baseado no aprendizado intuitivo e técnico da aeropônia e hidropônia como parte de uma aula de biologia as crianças desde seus 4 anos de idade. Assim a escola Hillside World Academy trabalha com o sistema de fazendinhas hidropônicas como instrumento pedagógico as crianças em aulas de ciência e biologia. Toda produção é utilizada pela própria escola para alimentação de alunos e professores, bem como ofertados as famílias dos alunos a um valor subsidiado.
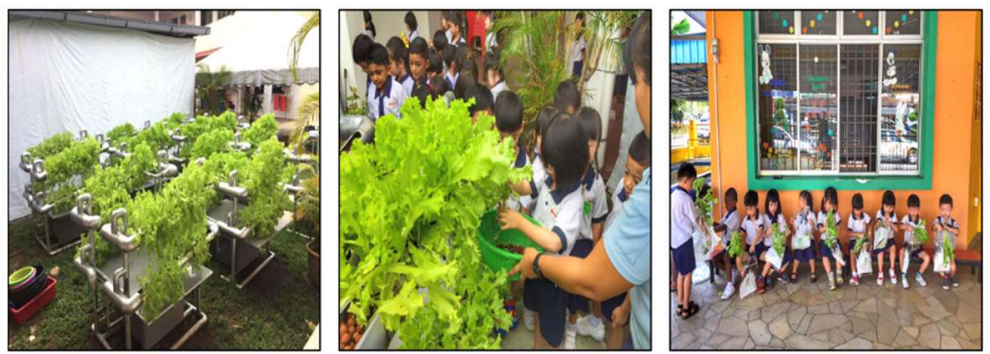

Figura 15: Fazendinha urbana escolar da Hillside World Academy em Singapura. 
Por fim, a fazenda vertical urbana APSN possui um sistema produtivo similar ao que é utilizado pela skygreens - 'Torre de vegetais ao céu', onde as minis - torres verticais (3m de altura) recebem água (solução nutritiva) que é bombeada (por um mini gerador) e redistribuída para girar 10 cremalheiras (prateleira de PVC para acomodação de vegetais). Toda operação de cultivo, colheita e limpeza das minis fazenda são realizadas pelos alunos portadores de necessidades especiais divididos conforme suas possibilidades de atuação na fazenda (ver fig.16).
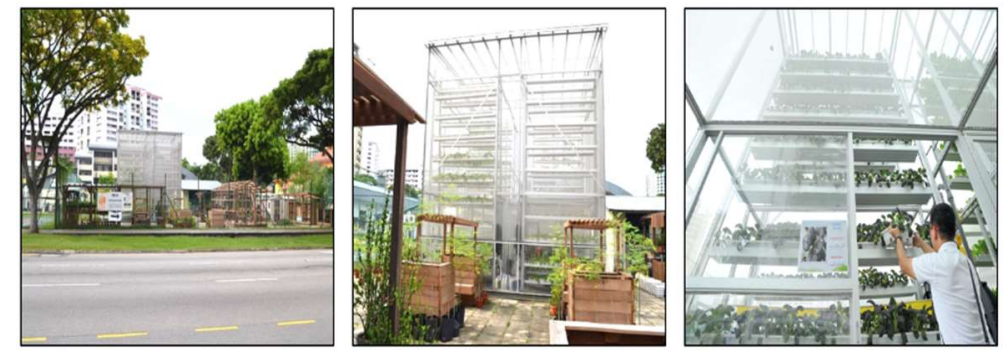

Figura 16: Fazenda urbana vertical da Associação de Pessoas com Necessidades Especiais - APSN de Singapura.

Atualmente a fazenda urbana APSN tem enfatizado sua produção no cultivo de espinafre, alface manteiga, tomatinhos e manjericão. Devendo ressaltar ao leitor que parte da produção da fazenda APSN é de uso exclusivo ao consumo da escola, uma vez que os vegetais são deslocados diretamente para a cozinha da associação onde outras turmas de alunos portadores de necessidades especiais realizam a prática da manipulação dos alimentos e transformação dos mesmos em pratos para degustação aos próprios alunos, professores e visitantes.

\section{DISCUSSÃO}

Antes de esboçar uma análise comparativa mais aprofundada sobre a atividade de agricultura urbana entre Singapura e Brasil (representado por Cuiabá/MT), desejo realizar um resgate teórico de um celebre pesquisador e cientista chamado Lefebvre ${ }^{4}$. Esse em sua obra 'La production de l'espace', retrata que dentro de um contexto urbano-industrial, a burguesia predomina enquanto classe dominante, e dispõe de duplo poder sobre o espaço: através da propriedade privada do solo e através da globalidade. Este controle do espaço pela alta burguesia exclui os pobres da propriedade fundiária [...] isso porque a classe que detém a maior parte dos recursos pode, através do dinheiro, ocupar, modelar e fragmentar o espaço da forma que melhor the convém. A maximização dos valores de troca produz benefícios desproporcionais para alguns grupos e diminui as oportunidades para outros (LEFEBVRE, 1986).

Castells (1983), complementa este conceito. Não há teoria do espaço que não seja parte integrante de uma teoria social geral, mesmo implícita. 'O espaço urbano é estruturado, quer dizer, ele não está organizado ao acaso, e os processos sociais que se ligam a ele exprimem, ao especifica-los, os determinismos de cada tipo e de cada período da organização social'.

\footnotetext{
${ }^{4}$ Foi um filósofo marxista e sociólogo francês. Estudou filosofia na Universidade de Paris, onde se graduou em 1920.A obra de Henri Lefebvre é bastante extensa (escreveu mais de 70 livros), abrangendo análises do marxismo no século XX à luz dos textos do próprio Marx, e mantendo intenso debate com grandes filósofos da época, como Sartre, SOTO (2013).
} 
O que se notou dado esse resgate teórico versado por Lefebvre quanto Casteells é que a atividade de agricultura urbana desenvolvida por Singapura quanto Brasil (representado por Cuiabá/MT), é fruto da influência do sistema econômico capitalista no espaço urbano ou perí-urbano, com base na necessidade do poder agroindustrial de 'modelar' a cidade de acordo com os seus interesses. Essa assertiva a quem estuda profundamente a atividade de agricultura urbana pode ser assim indagada: será possível não excluir a influência de outros agentes sociais no meio urbano dado a inserção positivista de uma agricultura urbana influenciada por um Estado regimentado e financiado através de um sistema capitalista imperfeito?.

A resposta à pergunta acima é bem fácil compreender através da atividade de agricultura urbana, mas ela também poderia se estender a outras atividades econômicas também, como: segurança pública, educação, entre outros. Isto é, no caso do Brasil (representado por Cuiabá/MT) presenciou uma agricultura urbana muito insipiente e políticas do Estado muito dispersas e pouco efetivas para promover o segmento. Dessa maneira, quando se analisa que o Estado deveria ser o agente fomentador a essa atividade e assim não o faz com eficiência, primeiro deve se perguntar qual Estado é esse? Quem são os agentes públicos que compõem as articulações desse Estado?. Basta analisar que o Estado brasileiro é uma extensão latifundiária controlado pelo capital em boa medida do meio rural extensionista patronal. Logo não é muito difícil compreender que a atividade de agricultura urbana no Brasil seja desarticulada e apenas sirva como instrumento pontual ao assistencialismo e estejam localizados em bairros periféricos, a fim de atender comunidades ou populações carentes. Ou seja, como o Estado brasileiro historicamente tem sido controlado por agentes públicos latifundiários donos do capital rural, o mesmo possui pouco estimulo e incumbência a promover políticas públicas de interesse 'macro urbano', focando assim incentivos as políticas públicas com maior incidência ao meio rural e quando urbano as áreas mais próximas a condomínios fechados, resorts privativos, shoppings, prédios públicos da alta administração.

Em Singapura não muito diferente aos preceitos teóricos de Lefebvre, presenciou uma atividade de agricultura urbana mais profissional, produtiva e geograficamente melhor distribuída nas regiões administrativas do país. Mas a mesma pergunta poderia se fazer, isto é, qual Estado é esse? Quem são os agentes públicos que compõem as articulações desse Estado?. O que presenciou é que o país não possui uma cultura histórica e iminentemente rural e o capitalismo Estatal de Singapura não é financiada e regimentada pelo capital latifundiário, ora o Estado está mais voltado a promoção do desenvolvimento urbano através de políticas públicas de interesse 'macro urbano'. Assim, o capital mesmo não tendo em sua essência o atendimento ao social, o mesmo consegue se dissipar de maneira mais proveitosa e acelerada das regiões urbanas para as regiões peri-urbanas do país.

Em síntese, os pressupostos de Lefebvre dentro de um contexto urbano-industrial, a qual afirma que a burguesia predomina enquanto classe dominante, isso porque a classe que detém a maior parte dos recursos pode, através do dinheiro, ocupar, modelar e fragmentar o espaço da forma que melhor lhe convém. Creio que esse pensamento de Lefebvre se aplica perfeitamente aos exemplos comparativos entre países como Brasil (representado por Cuiabá/MT) e Singapura, principalmente quando se faz a ligação que o controle do Estado está sob domínio presente da burguesia, restando apenas a identificar as características 
dessa burguesia para entender que tipo de agricultura urbana se aplica em cada país e suas finalidades de interesse social, ambiental e econômico.

Quadro 1: Análise comparativa entre as Fazendas Urbanas de Singapura e Brasil (representado por Cuiabá/MT).

\begin{tabular}{|c|c|c|c|c|}
\hline \multicolumn{5}{|l|}{ MATRIZ TÉCNICA COMPARATIVA } \\
\hline FAZENDAS URBANAS SINGAPURA & $\begin{array}{l}\text { Pontos } \\
\text { Favoráveis } \\
\text { (FV)* }\end{array}$ & $\begin{array}{l}\text { Empate } \\
\text { (E) }\end{array}$ & $\begin{array}{l}\text { Pontos } \\
\text { Favoráveis } \\
\text { (FH)* }\end{array}$ & FAZENDAS URBANAS CUIABÁ-MT \\
\hline $\begin{array}{l}\text { Custo de Implantação do } \\
\text { Considerado elevado }\end{array}$ & & & + & $\begin{array}{l}\text { Custo de Implantação do Projeto } \\
\text { Considerado moderado }\end{array}$ \\
\hline $\begin{array}{l}\text { Ciclo Produtivo das Culturas } 3 \text { semanas ( } 21 \\
\text { dias) }\end{array}$ & + & & & $\begin{array}{l}\text { Ciclo Produtivo das Culturas } \\
6 \text { semanas ( } 42 \text { dias) }\end{array}$ \\
\hline $\begin{array}{l}\text { Maximização da produção dado espaço } \\
\text { físico } \\
\text { (rende em média } 7 x \text { mais do que a produção } \\
\text { convencional) }\end{array}$ & + & & & $\begin{array}{l}\text { Moderada Maximização da } \\
\text { produção dado espaço físico } \\
\text { (há percas no processo produtivo) }\end{array}$ \\
\hline Ausência ao uso de defensivos agrícolas & + & & & $\begin{array}{l}\text { Utilização fracionada de defensivos } \\
\text { agrícolas }\end{array}$ \\
\hline $\begin{array}{l}\text { Elevado custo em energia elétrica } \\
\text { (Utilização de LED ou OLEDs para simular o } \\
\text { papel do Sol + funcionamento da central de } \\
\text { monitoramento de vegetais) }\end{array}$ & & & + & $\begin{array}{l}\text { Moderado Custo } \\
\text { em energia elétrica }\end{array}$ \\
\hline $\begin{array}{l}\text { Elevado Custo c/ Água + Solução Nutritiva } \\
\text { (captação de água via cisternas e da própria } \\
\text { rede pública) }\end{array}$ & & & + & $\begin{array}{l}\text { Custo zero c/ Água + Solução } \\
\text { Nutritiva (captação de água via } \\
\text { poço artesiano) }\end{array}$ \\
\hline $\begin{array}{l}\text { Produto produzido, embalado e Entregue ao } \\
\text { Cliente Final (Agregação de Valor) }\end{array}$ & + & & & $\begin{array}{l}\text { Produto Produzido e Entregue ao } \\
\text { Cliente Final (Semi - agregação de } \\
\text { Valor) }\end{array}$ \\
\hline $\begin{array}{l}\text { Portfólio de Produtos (média de } 10 \text { a } 15 \\
\text { tipos de culturas produzidas) }\end{array}$ & + & & & $\begin{array}{l}\text { Portfólio de Produtos (média de } 7 \text { a } \\
10 \text { tipos de culturas produzidas) }\end{array}$ \\
\hline $\begin{array}{l}\text { Baixo custo em Transporte (Entrega final do } \\
\text { produto ao cliente no próprio centro } \\
\text { urbano) }\end{array}$ & + & & & $\begin{array}{l}\text { Elevado custo em Transporte } \\
\text { (Entrega final do produto ao cliente } \\
\text { da zona peri-urbana } \\
\text { para zona urbana) }\end{array}$ \\
\hline $\begin{array}{l}\text { Comercialização da Produção (100\% via } \\
\text { contrato) }\end{array}$ & + & & & $\begin{array}{l}\text { Comercialização da Produção } \\
\text { Convencionalmente ( } \pm 90 \% \quad \text { via } \\
\text { mercado spot e } \pm 10 \% \text { via contrato) }\end{array}$ \\
\hline Cadeia Produtiva Integrada & + & & & Cadeia Produtiva Semi - Integrada \\
\hline Localização da Agroindústria (Urbana) & + & & & $\begin{array}{l}\text { Localização da Agroindústria } \\
\text { (Peri-Urbana) }\end{array}$ \\
\hline Viavelmente Econômica & & 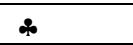 & & Viavelmente Econômica \\
\hline $\begin{array}{l}\text { Externalidades Positivas (Agroturismo + } \\
\text { Sustentabilidade + Ganho Social) }\end{array}$ & + & & & $\begin{array}{lr}\text { Externalidades } & \text { Positivas } \\
\text { (Agroturismo }+ \text { Sustentabilidade }+ \\
\text { Ganho Social) }\end{array}$ \\
\hline & $\sum F V=10(+)$ & $\begin{array}{l}\sum E=1 \\
(+)\end{array}$ & $\sum \mathrm{FH}=3(+)$ & \\
\hline
\end{tabular}

Dessa maneira, surgem algumas dúvidas. Qual modelo de agricultura urbana mais apropriada economicamente as grandes cidades ou entorno delas, se pudéssemos isentar ou neutralizar o papel do Estado como agente promotor do desenvolvimento de uma região?. A resposta para essa pergunta passa ser muito complexa quando se leva em conta as dimensões de riqueza e pobreza de cada país ou região. Assim, o mais apropriado ao pesquisador, com assim foi realizado nesse trabalho tenha sido realizar um comparativo técnico de formatos operacionais de fazendas urbanas mais produtivas entre regiões urbanas densamente povoadas. E a partir desses dados apreciar as vantagens ou pontos favoráveis representados pelo símbolo matemático (+), sempre levando em consideração tipos de fazendas urbanas de um país em relação a outro.

O quadro 1 mostra de uma maneira simplória, porém didático e intuitivo os inúmeros benefícios de 'Fazendas urbanas verticalizadas', (de terraço de prédios, de interiores) controladas e monitoradas em 
relação à 'Fazendas urbanas Horizontais', principalmente no que diz respeito à maximização da produção em relação ao espaço físico utilizado (Fazendas urbanas verticais produzem em média $7 x$ mais do que as horizontais dadas o mesmo espaço físico). Quanto ao 'ciclo produtivo dos vegetais' das Fazendas Urbanas Verticais, o mesmo tem sido metade daquele verificado numa Fazenda Horizontal. Convencionalmente as fazendas urbanas verticais são controladas e monitoradas e dado esse contexto produzem com 'ausência de defensivos agrícolas' em relação as fazendas horizontais. Os produtos das fazendas urbanas verticalizadas potencialmente 'possuem maior valor agregado' em relação as fazendas urbanas horizontais, uma vez que, o sistema agroindustrial verticalizado confecciona todo o processo produtivo em produzir, embalar e entregar ao cliente final os vegetais.

Outro ponto relevante observado na pesquisa diz respeito ao 'sistema de comercialização da produção' adotado pelas Fazendas urbanas de Singapura e Cuiabá (Brasil). Enquanto as fazendas urbanas singapurianas trabalham toda sua produção sobre o 'regime contratual', evitando riscos especulativos de mercado e assegurando um maior controle a solidez do seu fluxo de caixa, as Fazendas urbanas brasileiras (de Cuiabá/MT) trabalham sobre um 'regime de risco conhecido como mercado spot', no qual os acordos de compra e venda dos produtos são meramente informais e os preços estabelecidos conforme a oscilação da oferta e demanda de mercado, pois também foi identificado no Brasil (representado por Cuiabá/MT) fazendas urbanas sociais, cuja modalidade de vendas dos vegetais é ausente, tendo essas a função de consumo imediato e doações ao público mais carente. Fato esse já não observado na pesquisa in loco ao país de Singapura.

Quanto à 'formação da cadeia produtiva', percebeu-se nitidamente que as fazendas urbanas singapuriana se encontra organizada de maneira integrada, ou seja, as atividades de produção, comércio, logística e serviços estão cobrindo todos os estágios de uma cadeia de suprimento, desde a transformação de matérias-primas, passando pelos estágios intermediários de produção, até a entrega do produto acabado ao mercado consumidor. Já as Fazendas urbanas brasileiras (representado por Cuiabá/MT) deixam de agregar valor ao seu produto justamente por não ter em seu planejamento a integralização, o que faz com que seus produtos não passem por um processo final de acabamento e embalagem, determinando assim o repasse desse ônus ao consumidor final.

Do ponto de vista das 'externalidades positivas', as fazendas urbanas de Singapura têm apresentado efeitos social e cultural abrangentes, pois já fazem parte do roteiro de muitas agências de turismo urbano e gastronômico da Ásia por apresentar um 'layout turístico de produção sustentável e responsabilidade ambiental'. O mesmo não se observou nas Fazenda urbanas brasileira (representada por Cuiabá/MT), pois a mesma é muito menos tecnificada e com pouco apelo estético e arquitetônico a qual possa servir de incentivo ao turismo rural urbano.

Em relação à 'localização das agroindústrias', as fazendas urbanas singapurianas, por se localizar no centro do País-Estado-Cidade, se beneficia por estar muito próxima de seus clientes, permitindo que a cadeia produtiva seja mais curta e com maior eficiência no atendimento do consumidor final. Por outro lado, seus custos de instalação tornam-se maiores, uma vez que há uma tendência do preço de ocupação (utilização) 
do metro quadrado $\left(\mathrm{m}^{2}\right)$ ser mais elevado em decorrência das fazendas urbanas ocuparem um espaço físico no coração da cidade de Singapura. Já as Fazendas urbanas do Brasil (representado por Cuiabá/MT), as atividades de produção urbana de vegetais estão localizadas nos bairros periféricos ao grande centro urbano o que reduz substancialmente seus custos de implantação em decorrência do preço de ocupação (utilização) do metro quadrado $\left(\mathrm{m}^{2}\right)$ ser mais barato. Porém, perde em eficiência por estar relativamente mais distante de seus potenciais consumidores.

No que diz respeito ao 'portfólio de produtos', também há dois atenuantes, isto é, depende tanto das exigências de procura do próprio mercado por um determinado produto como depende do nível da própria agroindústria em eficiência e tecnologia para assumir uma produção diversificada com custos relativamente iguais como se fossem produzir de maneira comoditizada. No caso das fazendas urbanas de Singapura observou que as mesmas possuem elevado Know-how e devido a esse fator conseguem produzir vegetais em maior quantidade e em maior diversidade de culturas. Quanto ao que se observou no Brasil (representado por Cuiabá/MT), o nível tecnológico da agricultura urbana é praticamente nulo, bem como a preocupação com a gestão do negócio é bem pontual, ou seja, produz poucos variedades e tipos de vegetais para atender as necessidades marginais de um público específico, ou seja, o 'povão'. Pois, não observou preocupação as demandas privadas de redes hoteleiras, shoppings, restaurantes, entre outras instituições privadas.

\section{CONCLUSÕES}

Uma vez que, se espera a população humana global aumente nos próximos 50 anos alcançando o número de 9,5 bilhões de indivíduos, implicando na necessidade de obter $10^{9}$ hectares de terras adicionais, a fim de, produzir alimentos para toda humanidade, isto é, uma área aproximada ao tamanho do Brasil. É possível concluir que a atividade de agricultura urbana pode ser um importante mecanismo para auxiliar a segurança alimentar dos países e cidades densamente povoados. É concluso também que a atividade de agricultura urbana contribui de maneira significativa a Singapura quanto ao Brasil (representado por Cuiabá/MT), ao quesito emprego e geração de renda para milhares de pessoas, juntamente com uma série de benefícios ambientais, mesmo que indiretamente. Na verdade, no caso do Brasil dada a atual crise econômica a qual o país enfrenta, fontes alternativas de fornecimento de alimentos por meio da agricultura urbana precisam ser mais exploradas e promovidas com maior afinco pelo Estado, a fim de complementar as fontes existentes e fortalecer a agricultura familiar e demais cooperativas urbanas de produção de vegetais. E no caso de Singapura resta apenas aguardar o tempo para averiguar se todos os investimentos em tecnologia e em pesquisas de desenvolvimento tecnológico - P\&D redirecionados para atividades de agricultura urbana conseguirá aumentar a capacidade produtiva de vegetais do país, a fim de transformar Singapura em país autossuficiente até 2050.

\section{REFERÊNCIAS}

BARTHEL, S.; PARKER, J.; ERNSTSON, H.. Food and Green Space in Cities: A Resilience Lens on Gardens and Urban 
Environmental Movements. Urban Studies, v.52, n.7, p.1321-1338, 2015. DOI: https://doi.org/10.1177/0042098012472744

CASTELLS, M.. A questão urbana. Rio de Janeiro: Paz e Terra, 1983.

CAROLAN, M.; HALE, J.. 'Growing' communities with urban agriculture: Generating value above and below ground. Community Development, v.47, n.4, p.530-545, 2016. DOI: https://doi.org/10.1080/15575330.2016.1158198

FAO. Food Agriculture Organization: Urban Agriculture. São Paulo: Faostat, 2016.

GIL, A. C.. Técnicas de pesquisa em economia. 2 ed. São Paulo: Atlas, 1991.

IBGE. Instituto Brasileiro de Geografia e Estatística: Cidades. Brasília: Database, 2016

MARTIN, G.; CLIFT, R.; CHRISTIE, I.. Urban Cultivation and Its Contributions to Sustainability: Nibbles of Food but Oodles of Social Capital. Sustainability, v.8, n.5, p.409, 2016. DOI: https://doi.org/10.3390/su8050409

MCCLINTOCK, N.; MAHMOUDI, D.; SIMPSON, M.; SANTOS, J. P.. Socio-Spatial Differentiation in the Sustainable City: A Mixed-Methods Assessment of Residential Gardens in Metropolitan Portland, Oregon, USA. Landscape and Urban Planning, v.148, p.1-16, 2016. DOI: https://doi.org/10.1016/j.landurbplan.2015.12.008

MOUGEOT, L. J. A.. Agricultura Urbana - conceito e definição. Revista de Agricultura Urbana, v.1, p.1-8, 2000.

LEFEBVRE, H. D. L.. La production de l'espace. Paris: Anthropos, 1986.

LUCENA, L. P.; KLIEMANN NETO, F. J.; MASSUIA, F. M.; FANTI, L. D.. Avaliação Multicriterial das fazendas verticais canadenses como modelos sustentáveis de agricultura urbana. RAI: Revista de Administração e Inovação, v.11, n.1, p.181-202, 2014. DOI: https://doi.org/10.5773/rai.v11i1.1159

LUCENA, L. P.. Fazendas Urbanas I: Alternativa a Segurança Alimentar. Curitiba: Prismas, 2016.

LUCENA, L. P.. Modelo urbano de produção rural verticalizado como alternativa de segurança alimentar às grandes cidades: um estudo da viabilidade econômica e organizacional do modelo vertical canadense e do modelo horizontal brasileiro. Tese (Doutorado em Agronegócios) Universidade Federal do Rio Grande do Sul, Porto Alegre, 2015.
LUCENA, L. P.; KLIEMANN NETO, F. J.. A nova bioeconomia a partir das fazendas verticais: aspectos das vantagens competitivas do modelo alimentar vertical canadense sobre o modelo horizontal brasileiro. In: $3^{\circ}$ SIMPÓSIO DA CIÊNCIA DO AGRONEGÓCIOS - CEPAN. Anais. Porto Alegre: UFRGS, 2015b.

LORENZ, K.. Organic Urban Agriculture. Soil Science, v.180, n.4-5, 2015. DOI:

https://dx.doi.org/10.1097/SS.0000000000000129

PNUD. Programa das Nações Unidas para o

Desenvolvimento: Singapore Statistics. Singapore: ONU, 2017.

PÖLLING, B.. Comparison of Farm Structures, Success Factors, Obstacles, Clients' Expectations and Policy Wishes of Urban Farming's Main Business Models in North RhineWestphalia, Germany. Sustainability, v.8, n.5, p.446, 2016. DOI: http://dx.doi.org/10.3390/su8050446

POTHUKUCHI, K.; MOLNAR, S. A.. Sustainable Food Systems at Urban Public Universities: A Survey of U-21 Universities. Journal of Urban Affairs, v.37, n.3, p.341-359, 2015. DOI: https://dx.doi.org/10.1111/juaf.12149

RICHARDSON, R. J.. Pesquisa social: métodos e técnicas. 3 ed. São Paulo: Atlas, 1999.

ROGUS, S.; DIMITRI, C.. Agriculture in urban and peri-urban areas in the United States: Highlights from the Census of Agriculture. Renewable Agriculture and Food Systems, v.30, n.1, p.64-78, 2015. DOI: https://doi.org/10.1017/S1742170514000040

SOUTO, J. M. M.. Urban Agriculture: A new dimension of Agribusiness. Dissertação (Mestrado em Agronegócios) Universidade Federal do Rio Grande do Sul, Porto Alegre, 2017.

SPECHT, K.; SIEBERT, R.; HARTMANN, I.; FREISINGER, U. B. SAWICKA, M.; WERNER, A.; THOMAIER, S.; HENCKEL, D.; WALK, H.; DIERICH, A.. Urban agriculture of the future: an overview of sustainability aspects of food production in and on buildings. Agriculture and Human Values, v.31, n.1, p.3351, 2014. DOI: https://doi.org/10.1007/s10460-013-9448-4

SUPARWOKO; TAUFANI, B.. Urban Farming Construction Model on the Vertical Building Envelope to Support the Green Buildings Development in Sleman, Indonesia. Procedia Engineering, v.171, p.258-264, 2017. DOI: https://doi.org/10.1016/i.proeng.2017.01.333

WARMING, M.; HANSEN, M. G.; HOLM, P. E.; MAGID, J.; HANSEN, T. H.; TRAPP, S.. Does intake of trace elements through urban gardening in Copenhagen pose a risk to human health? Environmental Pollution, v.202, p.17-23,

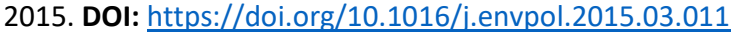

A CBPC - Companhia Brasileira de Produção Científica (CNPJ: 11.221.422/0001-03) detém os direitos materiais desta publicação. Os direitos referem-se à publicação do trabalho em qualquer parte do mundo, incluindo os direitos às revã̃es, expansões e disseminac̃oes da contribuiç̃o, bem como outros direitos subsidiários. Todos os trabalhos publicados eletronicamente poderão posteriormente ser publicados em coletâneas impressas sob coordenação da Sustenere Publishing da Companhia Brasileira de Produção Científica e seus parceiros autorizados. Os (as) autores (as) preservam os direitos autorais, mas não têm permissão para a publicação da contribuição em outro meio, impresso ou digital, em português ou em tradução. 